\title{
AN UNUSUAL TYPE OF GORTICAL GLIOSIS
}

\author{
$\mathrm{By}$
}

\author{
R. M. STEWART
}

\section{LEAVESDEN}

THE peculiar type of cerebral gliosis which is the subject of the present communication was discovered postmortem in a case of muscular dystrophy, and is of special interest in its possible relationship to tuberous sclerosis, which may perhaps be regarded as the prototype of those developmental diseases in which circumscribed overgrowth of neuroglia is the outstanding feature. In addition to the pathological interest of the case, the terminal phase of the patient's illness was marked by the appearance of clinical features of a most bizarre character, and for this reason it has been thought well to record the clinical history in some detail.

\section{PERSONAL GASE}

History.-A. L., a feebleminded adult, age 21, was admitted to Leavesden Mental Hospital on August 10, 1922. A history was obtained of progressive muscular weakness commencing in his eighth year and limited, at first, to the right upper and lower limbs. For some years the loss of power was very slight and not sufficient to prevent his attendance at school. By the age of 14, weakness and wasting had made their appearance in all four limbs, and he now had difficulty in walking and was unable to undertake any form of outdoor work. In 1917 he was admitted to the National Hospital, Queen Square, under the care of Dr. Risien Russell. On his discharge from hospital he remained at home until his certification and admission to Darenth Training Colony in May, 1920. Here it was noted that he had had a fair education and that his mental defect seemed to depend on the disabilities he had suffered on account of his health, but was of a kind indicating the need for care, supervision and control.

Physical examination revealed the following : Height, 5 feet 4 inches. Weight, 6 st. Circumference of head, $22 \frac{1}{2}$ inches. Speech slow and deliberate. Pupils and cranial nerves normal. Weakness and marked muscular wasting in shoulder girdles, upper arms and both lower limbs. Knee-jerks absent. Plantars normal. No sphincter trouble. The patient spent all his time in a wheel-chair and was able to do useful work in the tailor's shop.

In 1924 his condition was noted to be as follows : A delicate-looking youth with only slight mental enfeeblement. He can read, write and spell simple words, but is poor at describing common objects. Mental age by the Binet Simon scale, 10 years. There is a moderate growth of hair on the upper lip and his cheeks are somewhat swollen in the position of the parotid glands; he suffers from pyorrhœa. Articulation is deliberate and slightly indistinct. Expression rather fixed and staring, with weakness of nasolabial folds.

Pupils and cranial nerves normal. No sensory disturbance. Marked wasting of pectorals and deltoids. Upper arms diffusely wasted; the head of the humerus can 
be readily dislocated from the glenoid cavity by passive movement. The patient is able to write a good hand ; feeds himself and occupies his time by sewing buttons on clothing. Lower limbs : marked hypotonia and muscular wasting, more on the right side. Legs too weak to support weight of body. Right heel cannot be raised off bed, nor can he turn on his side. Sitting posture can be maintained. Abdominal and plantar reflexes normal. All deep reflexes absent. Sphincters normal. His skin is dry and the areolæ of his nipples are small and oval. Blood pressure, $110 / 60 \mathrm{~mm}$. Urine normal. Wassermann reaction negative in blood and cerebrospinal fluid. Blood : R.B.C., 4,840,000; W.B.C., 10,500; polymorphs, 65.5 per cent.; large lymphocytes, 8.5 per cent. ; small lymphocytes, 25 per cent. ; eosinophils, 0.5 per cent.

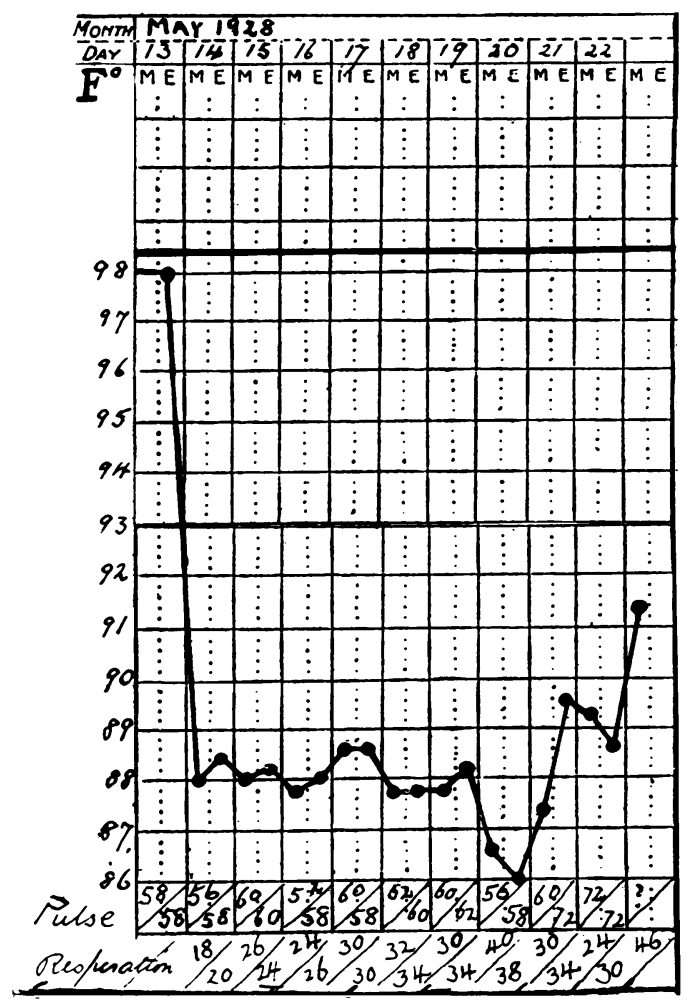

Fig. 1.-Chart of terminal phase of illness. Rectal temperature.

Progress.-There was no material alteration in his physical or mental state until December 22, 1927, when he was stated to have had a number of seizures of an epileptiform character during the night. These were accompanied by profound mental deterioration, so that he ceased to take any interest in his surroundings, became faulty in his habits and vomited frequently. From December 26 until January 7 he remained in a state of stupor with slow feeble pulse and shallow respiration, and a body temperature so low that the ordinary clinical thermometer failed to register. His general appearance resembled that of a person suffering from profound shock. On January 7 a sudden and marked improvement took place; his temperature rose to normal, his pulse became stronger and its rate, which during the period of stupor had been between 
50 and 64, rose to 78. At the same time his mental state improved, and on January 18, when he was allowed up, he seemed to be quite himself again.

On May 13 thère was a sudden relapse ushered in by an attack of hæmatemesis and rapid fall of temperature. On May 14 his condition was as follows : He lies in a state of stupor, groaning occasionally, not entirely unconscious, but unable to speak. Rectal temperature, $88^{\circ} \mathrm{F}$. Respirations, 18, shallow and irregular. Pulse 56, small and feeble. Blood pressure, $60 / 40 \mathrm{~mm}$. Pin-point pupils. Left oculocardiac reflex gives a rate of 44 during compression. Swallowing difficult. Profuse sialorrhœea. The skin everywhere feels icy cold and, except on the face, does not bleed when pricked. A drop of 4 per cent. cocain in the right eye caused a very slight dilatation of the pupil after the lapse of five hours. There is complete muscular relaxation, retention of urine and obstinate constipation. All superficial and deep reflexes are absent. In this state, with a rectal temperature never above $89^{\circ} \mathrm{F}$. (fig. 1), he continued until May 21, when signs of bronchopneumonia were detected. The rectal temperature rose several degrees, he continued to vomit repeatedly, and death occurred at 12.50 p.m. on May 23:

\section{REPORT OF AUTOPSY}

A post-mortem examination was held three hours after death. A marked degree of muscular wasting was present in the shoulder and pectoral regions, the upper arms and the anterior aspects of the thighs. There were slight contractures at the knee joints. The fascia clothing the anterior thoracic wall was thickened and the affected muscles yellowish-white on section. Those most diseased included pectoralis major (clavicular portion less profoundly affected), pectoralis minor, serratus magnus, latissimus dorsi, deltoids, spinati, sternomastoids, omo- and sternohyoids, levator anguli scapulæ, trapezius, including upper third. Probably the triceps, biceps, supinator longus, glutei and certain muscles of the anterior aspect of the thigh were also affected, but these were not exposed. Unaffected muscles included the abdominals, diaphragm, multifidus, semispinalis, complexus, splenius capitis, muscles of the lower jaw and scalp.

Both lungs showed a condition of acute lobular pneumonia. The heart $\left(8 \frac{1}{2}\right.$ oz.) appeared normal, save for a little fatty infiltration near the apex. The liver, much reduced in size, weighed $29 \frac{1}{2} \mathrm{oz}$. and showed cloudy swelling. The kidneys were also small ( $3 \frac{1}{2} \mathbf{~ o z}$.), and the right contained a large calculus. Spleen (4 $\frac{1}{2} \mathrm{oz}$.) normal. Both submaxillary glands were moderately enlarged. The pituitary, thyroid, pancreas and suprarenal glands were normal. No renal or other tumours were found.

Examination of the Nervous System.-The brain weighed $49 \frac{1}{2}$ oz. Slight thickening of the pia-arachnoid existed in the interpeduncular space. The cerebral hemispheres were symmetrical, large, firm and well convoluted. Scattered over the grey matter on the fore part of the brain were numerous small circular and slightly raised wart-like plaques, each a little paler than the surrounding cortex and varying in size from that of a pinhead to areas measuring $2 \mathrm{~mm}$. in diameter (fig. 2). Most numerous and largest on the mesial surface of the hemisphere, they diminished in number from before 
backwards, and behind the post-central gyri no plaques were found. The largest showed slight umbilication, but nowhere was there any tendency to distort the convolution pattern. The frontal convolutions did, however, show widening of the sulci, and in this situation it was obvious to the touch that there was a certain amount of diffuse sclerosis. Fewer plaques were found on the convex surface of the hemisphere, and on section no gross abnormalities were found. The walls of the lateral ventricles had a rough

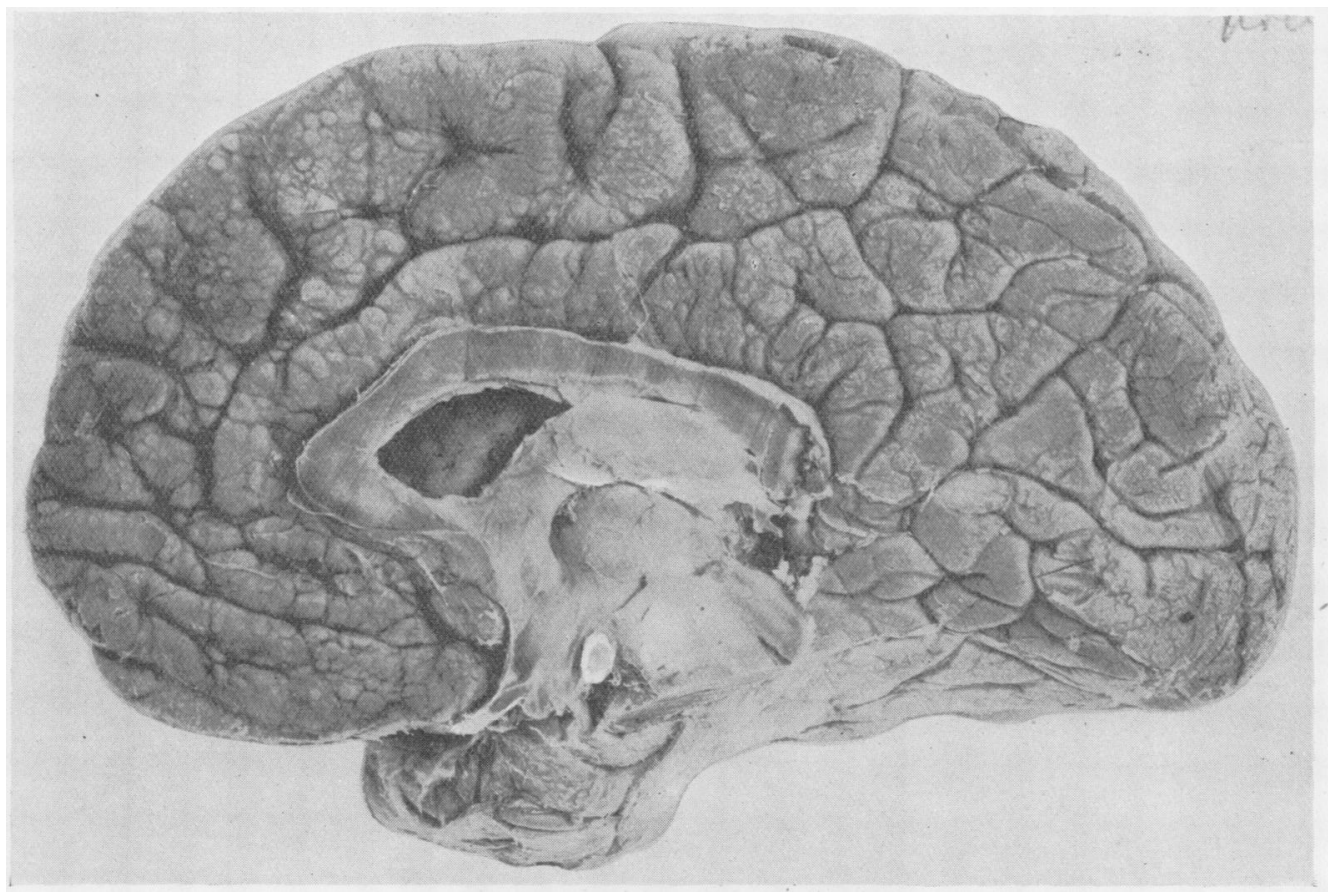

Fig. 2.-Mesial surface of left cerebral hemisphere showing the presence of wartlike plaques on the surface of the grey matter of the frontal convolutions.

uneven surface, but no tumours were present. No abnormalities were found in the cerebellum, pons, medulla and spinal cord.

Microscopic Examination.-Examination of sections taken from frontal cortex free from nodules showed a considerable amount of subpial fibrillar gliosis.

The plaques were composed almost entirely of fine neuroglial fibres, either loosely intertwined or more densely matted together with an accompanying increase of glial nuclei. Towards the deeper aspect of these masses large astrocytes were particularly numerous, and in some situations the proliferation of glial fibres seemed to be especially related to the smaller cortical bloodvessels as they entered the grey matter from the pia; in a 
number of localities the appearance was as though the cortex had been drawn in by dense strands of glial tissue (fig. 3). Both in and beneath these masses-which in most instances extended no deeper than the fourth cortical layer-the normal columnar arrangement of nerve-cells was considerably disturbed, either through the actual disappearance of nerve-cells or their altered polarity; in one plaque taken from the second frontal convolution these changes were particularly well marked, the nerve-cells being twisted in

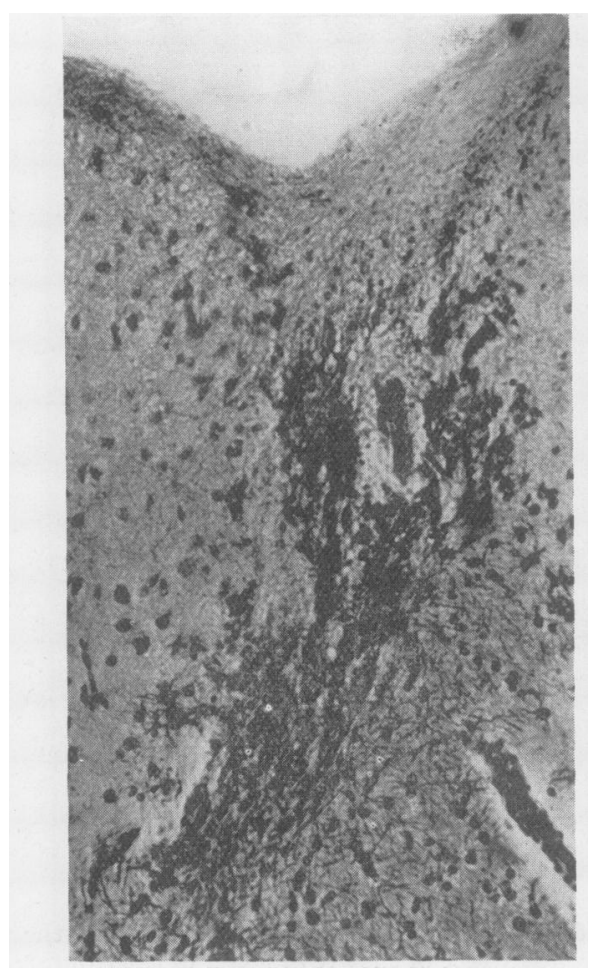

Fig. 3.-Cortical area of gliosis showing dense strands of neuroglial fibrils. Silver impregnation.

all directions (fig. 4). Here also was found a nest of elongated pyramidal cells with their long axes horizontally disposed, and at a deeper level large numbers of cells rounded in outline, possessing several short broad protoplasmic processes and large vesicular nucleus with conspicuous nucleolus ; their appearance suggested developing neuroblasts (fig. 5).

Careful search failed to reveal the presence of either the large gliogenous elements or the giant multipolar cells which are found in most cases of tuberous sclerosis. The nerve-fibres entering the neighbourhood of sclerotic areas showed poorly staining and sometimes irregular myelin sheaths. The 
underlying white matter showed relatively little gliosis. The bloodvessels appeared normal.

\section{DISGUSSION}

The chief interest of the clinical symptoms, particularly of those which were terminal, lies in their close resemblance to the picture of acute vagotonia. According to Eppinger and Hess, ${ }^{1}$ in the normal individual there

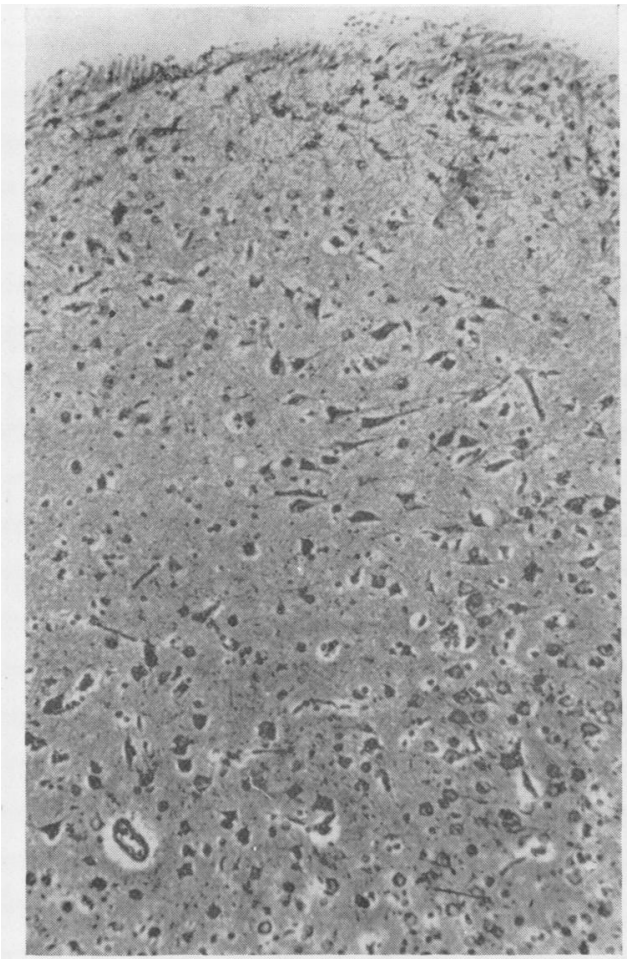

FIG. 4.-Section of grey matter of second frontal convolution showing from above downwards : (a) superficial gliosis, $(b)$ a small group of horizontally disposed nerve-cells, $(c)$ irregularly disposed neuroblasts. Silver impregnation.

exists a state of balance between the two divisions of the autonomic nervous system; in the vagotonic subject this equilibrium is disturbed, so that a condition of increased tone is established in the parasympathetic system, which is expressed clinically by certain signs, prominent among which are acute myosis, a positive oculocardiac reflex, salivation, pallor of the skin, hypothermia and obstinate constipation.

Now these were precisely the symptoms present in the case reported above, and on the basis of the hypothesis formulated by Eppinger and Hess certain of the symptoms exhibited in mode of dying might perhaps be regarded 
as a manifestation either of overwhelming hyperactivity of the parasympathetic system or of a relatively sudden failure of the sympathetic system. With regard to the existence of the former state, no evidence is to be found in the records of clinical medicine, but for the other condition there is something to be said - the symptoms of adrenal apoplexy possibly affording an example of sudden failure of the sympathetic-though, so far as the writer is aware, in no previously reported cases of muscular dystrophy have similar symptoms been observed. Nevertheless, without entering too far into the realm of pure speculation, it is perhaps permissible to suggest, as an explanation of certain of the clinical features, the possibility of a rapid failure of the

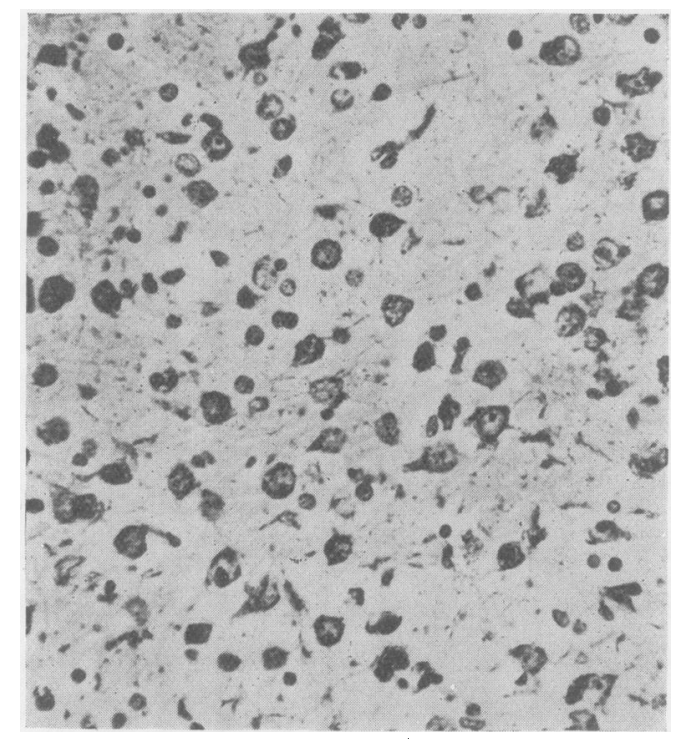

Fig. 5.-Neuroblasts from the deeper cortical layers as shown in fig. 3, but under a higher magnification. $\times 500$. Silver impregnation.

sympathetic in this disease. On this basis, the myosis, tachycardia, vomiting and excess of salivary secretion could be regarded as due to the unopposed action of the parasympathetic, but other features of the case are not so easily explained, and the ashen pallor and coldness of the extremities might just as readily be attributed to the profound fall in blood pressure which occurred in the terminal phase of the patient's illness.

It is interesting to recall that in his Bradshaw lecture E. Bramwell 2 suggested the possibility of an implication of the sympathetically innervated elements in muscle structure as an ætiological basis for muscular dystrophy, and there can be few neurologists who have not observed in this disease clinical data indicative of neuroglandular disturbance. For the most part, spinal cord findings in previously reported cases of myopathy have been 
negative, but little detailed examination appears yet to have been made of the cells and fibres of the sympathetic system. With this comparatively neglected field in mind, the study of the entire autonomic nervous system

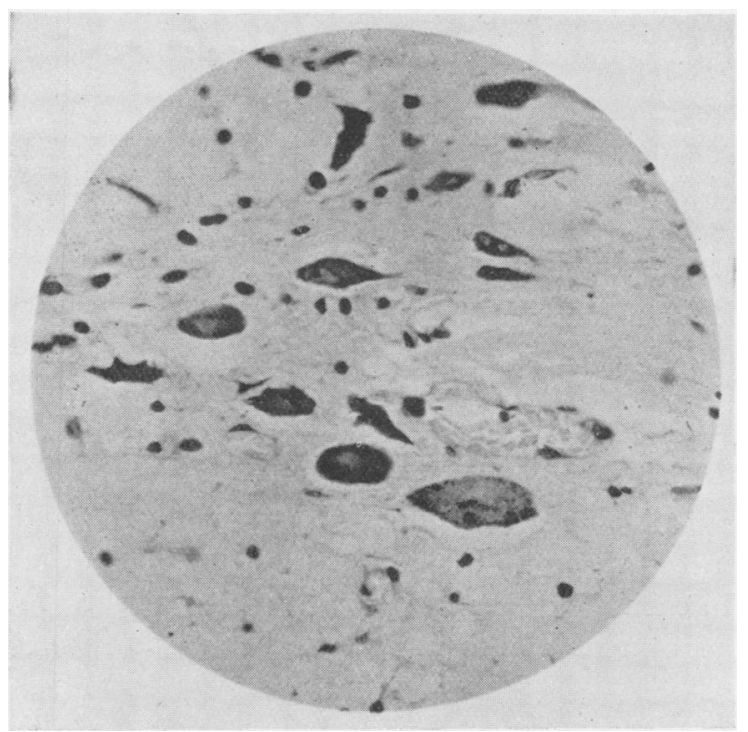

Fig. 6.-D.8 segment of cord. Intermediolateral cell column showing chronic cell degeneration. Cresyl violet stain.

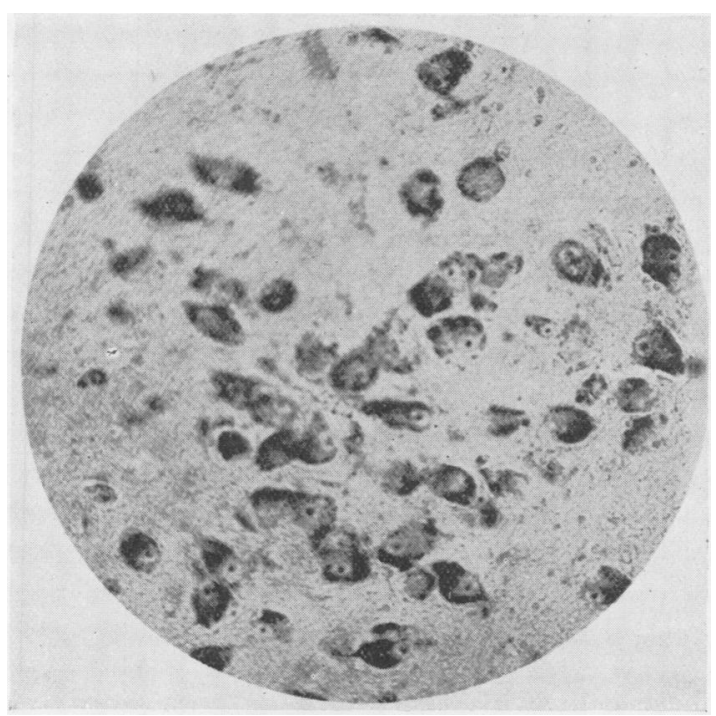

Fig. 7.-Hypothalamus. Nerve-cells from the grey matter of wall of third ventricle. 
was made part of the scheme of investigation ; for various reasons the work had to be abandoned.

Reference may, however, be made to the condition of the sympathetic

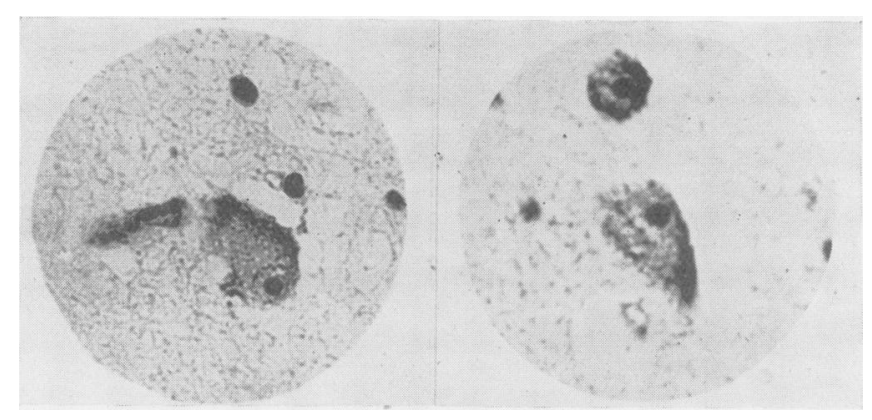

Fig. 8. - Nerve-cells in dorsal vagal nucleus. $\times \mathbf{5 6 0}$.

cells of the intermediolateral cell column in segments D.8 and L.1, to those in the anterior part of the hypothalamus and to the cells of the dorsal nucleus of the vagus. In each of these situations evidence of chronic cell shrinkage with lateral displacement of the nucleus was obvious (figs. 6, 7, 8), but a

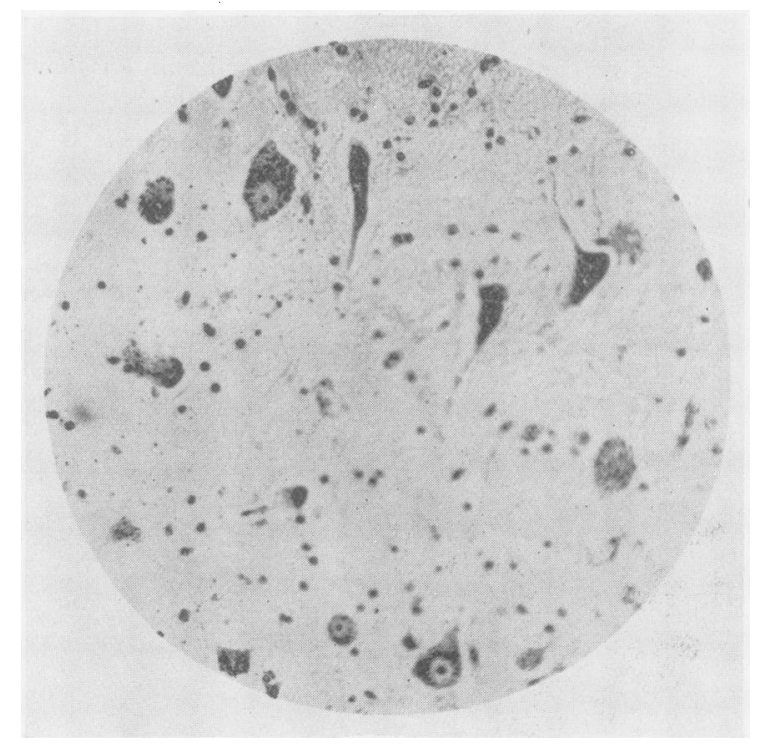

Fig. 9.-Spinal cord. D.1. Anterior horn cells.

comparison of these cells with the larger anterior horn cells of the cord (fig. 9) showed that the neuronic degeneration was widespread and not limited to those concerned with the activity of the autonomic nervous system. 
Lastly, it is necessary to mention the enlargement of the salivary glands which was present in this case. To avoid disfigurement of the body, sections were taken from the submaxillary and not from the parotid glands. No obvious changes were noted, and the significance of this enlargement remains obscure. Sialorrhœa was a striking feature in the clinical course, but it was more or less terminal and the salivary enlargement preceded it by some years without excessive secretion, so that the enlargement could hardly be attributable to a long-continued state of autonomic stimulation. The condition appears to have been only once previously observed. Under the title 'A case of Erb's juvenile dystrophy associated with bilateral enlargement of the

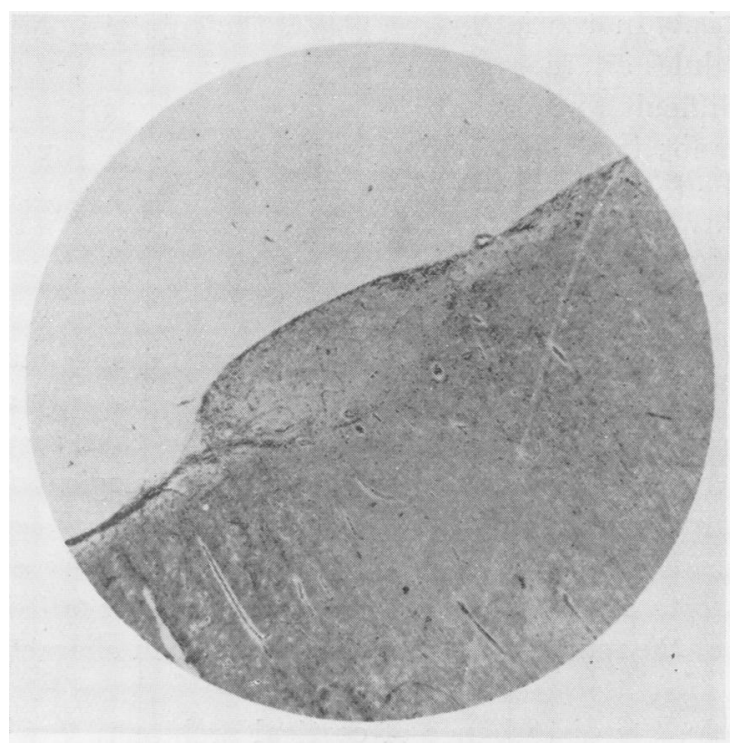

FIG. 10.-Appearance of cortical plaque. Note its limitation to the superficial layers of the grey matter. Silver impregnation.

parotid and submaxillary glands,' Mitchell Clarke ${ }^{3}$ in 1903 reported the presence of symmetrical enlargement of the salivary glands in a youth of 18 . The onset of the muscular atrophy and swelling was simultaneous, a coincidence which suggested to the author the possibility of some common cause for the two conditions.

\section{GORTIGAL GHANGES-GEREBRAL HEMISPHERES}

The most striking naked-eye change consisted in the presence of several hundred small, circular, raised wart-like plaques which seemed to be on, rather than in, the substance of the grey matter (fig. 10). Particularly numerous on the frontal convolutions, they were much fewer on the more caudally placed convolutions, and none was found on the occipital convolu- 
tions. The majority of plaques were about $1 \mathrm{~mm}$. in diameter and the largest were little more than twice this size. All were readily recognized by inspection. even after prolonged formalin fixation. In addition, on the mesial surface of the frontal lobe indication of a diffuse gliosis was shown by narrow gyri separated from each other by deep fissures. On section, the cortex showed no loss of the sharp line of demarcation which normally separates grey matter from white, the sclerotic process involving principally the upper layers and leaving the architecture of the deeper portion of the cortex undisturbed. The walls of the lateral ventricle showed slight irregularity but no ' candle guttering' or infiltrating tumours of the type seen in tuberous sclerosis.

These appearances are in marked contrast with those encountered in tuberous sclerosis. In the latter condition, the hypertrophic convolutions and sclerotic nodules are more easily felt than seen, and in hardened brains are extremely difficult to pick out; in diameter they are seldom less than $\frac{1}{2} \mathrm{~cm}$., and are not infrequently very much larger. Their distribution is without reference to any particular cortical region, and when sectioned it is seen that they blend with the underlying white matter.

In its microscopical characters the case reported here showed two points of similarity - a reaction of the surface neuroglia and disturbance of cortical architecture ; here the resemblance ended, and numerous points of difference were obvious. The raised wart-like nodules occupying only a portion of a convolution presented an appearance quite unlike that seen in tuberous sclerosis; the transition between normal and pathological fields was not gradual but abrupt, and usually took place in the superficial cortical layers. Groups of atypical nerve-cells resembling neuroblasts were encountered in the superficial strata of the cortex, but a diligent search failed to reveal the presence of any of the remarkable large elements which characterize tuberous sclerosis.

On the whole, the disturbance of cortical architecture was more widespread but much less severe than in the latter condition, and the macroglial reaction decreased in a gradual and progressive way as one followed the convolutions from the frontal to the occipital poles.

Gliosis as a developmental abnormality is by no means an uncommon finding in the brain of the mental defective, and a study of the microscopical appearances in this case suggests that we are here dealing with an unusual type of generalized glial hyperplasia limited to the grey matter of the cerebral cortex and probably congenital in origin.

\section{SUMMARY}

A feebleminded male with Erb's juvenile type of muscular dystrophy died after the disease had been in existence for 20 years. During life the patient exhibited a bilateral and symmetrical enlargement of the salivary glands. The terminal illness was ushered in by a marked and persistent hypothermia, bradycardia, low blood-pressure, profuse salivation, repeated 
vomiting, myosis and a positive oculocardiac reflex; it is suggested that a sudden failure of the autonomic nervous system may have caused these unusual terminal symptoms.

Pathological examination confirmed the diagnosis of muscular dystrophy, and, in addition, revealed the presence in both cerebral hemispheres of a special type of glial hyperplasia ; this took the form of small, raised wart-like nodules in the cortical grey matter, numerous in the frontal convolutions and diminishing in number towards the occipital poles, in many situations accompanied by a disturbance of cytoarchitecture and by the presence of primitive nerve-cells. No glial or neuronic cells of giant type were found and the visceral organs contained no tumours.

The condition appeared to represent an unusual type of primary gliosis rather than an abortive form of tuberous sclerosis.

\section{REFERENGES}

1 Eppinger, H., and Hess, L., Vagotonia, 1915.

2 Bramwell, E., Lancet, 1925, $2,1103$.

3 Mitchell Clarke, J., Brain, 1903, 26, 202. 